\title{
TEMPERATURA E UMIDADE DO SOLO EM SISTEMA DE INTEGRAÇÃO SOJA-BOVINOS DE CORTE COM DIFERENTES MANEJOS DA ALTURA DO PASTO
}

\author{
Soil temperature and soil moisture in crop livestock systems with different forage management height \\ João de Andrade Bonetti ${ }^{*}$; Ibanor Anghinoni²; Lucas Zulpo ${ }^{3}$

\begin{abstract}
${ }^{1}$ Doutorando; Departamento de Solos; Universidade Federal do Rio Grande do Sul; e-mail (*agro.bonetti@gmail.com) ${ }^{2}$ Professor; Departamento de Solos; Universidade Federal do Rio Grande do Sul; e-mail (ibanghi@ufrgs.br)

${ }^{3}$ Doutorando; Departamento de Solos; Universidade Federal do Rio Grande do Sul; e-mail (lucaszulpo@yahoo.com.br)
\end{abstract}

Artigo enviado em 10/03/2017, aceito em 21/04/2017 e publicado em 07/07/2017.

RESUMO: O manejo de bovinos em sistemas integrados de produção agropecuária reduz a biomassa, podendo alterar a dinâmica dos atributos do solo. O objetivo desse trabalho foi avaliar os efeitos relacionados à altura de manejo do pasto, na cobertura, umidade e temperatura do solo, durante o pastejo e o cultivo de soja. A altura de manejo do pasto foi de 10, 20,30, $40 \mathrm{~cm}$ e sem pastejo. Os atributos de solo foram determinados nas camadas 0-5, 5-10 e 10-20 cm, sendo; caracterização física, umidade volumétrica do solo e temperatura do solo com uso de geotermômetros no período noturno e diurno. A biomassa sobre o solo, no ciclo de pasto, foi determinada coletando amostras a cada mês. As diferentes intensidades de pastejo reduziram a biomassa sobre o solo, sendo que no mês de setembro a biomassa residual foi de $0,48 \mathrm{Mg} \mathrm{ha}^{-1}$ no pasto mantido a $10 \mathrm{~cm}$ de altura e $5,81 \mathrm{Mg} \mathrm{ha}^{-1}$ no sem pastejo. A umidade do solo foi pouco alterada, sendo esse resultado relacionado a precipitação regular e acima da média regional. A maior temperatura do solo no início do cultivo do pasto e da soja foi observada nas áreas com maior intensidade de pastejo. A redução da biomassa do pasto, em função do pastejo, proporcionou maior temperatura do solo durante o dia e menor durante a noite, fato que aumentou a amplitude térmica, especialmente no pasto mantido a 10 e $20 \mathrm{~cm}$ de altura.

Palavras-chave: Biomassa de pastagem, integração lavoura pecuária, amplitude da temperatura do solo.

\begin{abstract}
Crop livestock systems can reduce the biomass, and effect soil dynamics. The objective of this study was evaluating the impact of animals grazing in biomass residue, soil moisture and soil temperature during pasture and soybean. The grazing was managed at 10,20,30,40 cm height, and no grazing. Soil physics characterization, soil moisture and soil temperature was determined in depth increment to 0-5, 5-10 and 10-20 cm. Biomass during pasture was determined one time for month. Pasture management reduce the biomass over soil, and in September was 0.48 $\mathrm{Mg} \mathrm{ha}^{-1}$ in pasture at $10 \mathrm{~cm}$ and $5.81 \mathrm{Mg} \mathrm{ha}^{-1}$ in no-grazing management. Soil moisture was not several affected by pasture management, especially because the regular precipitation during this study. Soil temperature was increased in intensity pasture during initial development of oat and soybean. Biomass reduction during grazing increase the soil temperature during day, and reduce during at night, and this has been the reason for the greater temperature variation day-night.
\end{abstract}

Keywords - Grass biomass, crop livestock systems, variation of soil temperature.

\section{INTRODUÇÃO}

No plantio direto (PD) e nos sistemas integrados de produção agropecuária (SIPA), o cultivo de plantas o ano todo protege o solo das intempéries climáticas. Uma diferença significativa ocorre no SIPA, onde o pastejo dos animais reduz a biomassa, podendo, em determinados períodos, reduzir a proteção do solo interferindo na umidade e na temperatura do solo (Ts) (VEIGA; REINERT; REICHERT, 2010).
A redução da biomassa sobre o solo foi observada no SIPA no Sul do Brasil, onde o manejo do pasto a $10 \mathrm{~cm}$ de altura apresentou, no final ciclo de pastejo, biomassa seca residual de $1,5 \mathrm{Mg} \mathrm{ha}^{-1}$, enquanto que no pasto mantido a $30 \mathrm{~cm}$, a biomassa residual foi de 4,5 Mg ha-1 (MARTINS et al., 2015). Portanto, a redução da cobertura do solo pelo pastejo é dependente do manejo da altura do pasto, que pode ainda afetar a estrutura física do solo (BONETTI et al., 2015) e reduzir o fluxo de calor no solo. Esse fato se torna importante, principalmente, devido ao período que sucede a retirada 
dos animais ser a semeadura das culturas de verão. A absorção da energia solar depende da intensidade da radiação e da absortividade e refletividade do solo, que tem relação com a presença ou ausência da biomassa em sua superfície (CARNEIRO et al., 2014). Após ser absorvida, a energia solar é transmitida para as camadas do solo e esse processo é dependente das propriedades térmicas do solo, como o calor especifico, a condutividade térmica e a relação entre essas propriedades (difusividade térmica). As alterações são maiores na camada até $10 \mathrm{~cm}$, a qual concentra a maior parte das raízes e atividade dos microrganismos. Entre as camadas, a transferência de calor é controlada pelos mecanismos de condução e convecção e com a alteração na estrutura física, esses processos podem agir de diferentes formas no solo. O fluxo de calor depende da capacidade e da condutividade térmica do solo, que variam com a composição, a densidade e o teor de água no solo. $\mathrm{O}$ aquecimento do solo pode reduzir a umidade do solo, que afeta a respiração dos microrganismos e o crescimento de raízes (BAO et al., 2016)

A condutividade térmica da parte mineral do solo, da água e do ar é, em média, 1,7; 0,6 e 0,026 W/ (m $\left.{ }^{\circ} \mathrm{K}\right)$, respectivamente, indicando que o calor se transfere, principalmente, através das partículas sólidas. Em solos compactados e com menor umidade, como em manejo intensivo do pasto, ocorre alterações no fluxo de calor, porque as partículas do solo têm uma menor capacidade de calor e maior condutividade térmica em relação a água, indicando que solos, secos nessas condições, ficam mais rapidamente quentes e frios do que os solos úmidos (LICHT; AL-KAISI, 2005). Portanto, é importante manter o equilíbrio entre a estrutura física e a manutenção da umidade do solo, adequado para a produção agrícola, porque esses fatores estão relacionados às alterações na Ts.

Quantificar os efeitos do sistema de manejo na temperatura, na umidade e na compactação do solo pode ajudar a explicar algumas diferenças no desenvolvimento das plantas (LICHT; AL-KAISI, 2005), principalmente devido a escassez de estudos de temperatura do solo. O objetivo desse trabalho foi avaliar os efeitos da altura de manejo do pasto, na cobertura, umidade e temperatura do solo, durante o pastejo e o cultivo de soja.

\section{MATERIAL E MÉTODOS}

A área experimental fica localizada no município de São Miguel das Missões-RS, 2903'10" S, $53^{\circ} 50^{\prime} 44^{\prime \prime} \mathrm{O}$, com altitude média de $465 \mathrm{~m}$, clima subtropical úmido e quente (Cfa) segundo a classificação de Köppen (Kottek et al., 2006), com temperatura média anual de $19^{\circ} \mathrm{C}$ e precipitação média anual de $1850 \mathrm{~mm}$ (CEMETRS, 2017). No período de realização deste estudo, abril de 2014 a abril 2015, a temperatura média foi de $19,7^{\circ} \mathrm{C}$ e a precipitação de $2280 \mathrm{~mm}$. O solo é classificado como Latossolo Vermelho Distroférrico (EMBRAPA, 2013) profundo, bem drenado, cor vermelho-escura e o relevo é ondulado a suavemente ondulado com declividade entre 0,02 a $0,10 \mathrm{~m} \mathrm{~m}^{-1}$.

O manejo em semeadura direta iniciou em 1993 com cultivo de aveia preta (Avena strigosa, Schre) no inverno, para produção de sementes e soja (Glycine max) no verão. No ano de 2001 iniciou o SIPA com consorcio de aveia preta e azevém (Lolium multiflorum, Lam.) no inverno pastejada por bovinos e manutenção do cultivo de soja no verão. A área total do experimento é de 22 hectares, dividida em parcelas variando de 0,8 a 3,5 hectares para o pastejo dos animais e 0,1 hectares para manutenção do SPD sem pastejo (SP). O delineamento experimental utilizado foi o de blocos ao acaso, com três repetições, onde os tratamentos foram definidos pelo manejo da altura do pasto no inverno, sendo: a 10, 20, 30, $40 \mathrm{~cm}$ (tratamentos P10, P20, P30 e P40, respectivamente) e SP.

Em 17 abril de 2014, no cultivo de inverno, foi semeada $60 \mathrm{~kg} \mathrm{ha}^{-1}$ de aveia preta objetivando atingir 300 plantas $/ \mathrm{m}^{2}$, com adubação de $60 \mathrm{~kg} \mathrm{ha}{ }^{-1}$ de $\mathrm{P}_{2} \mathrm{O}_{5}, 90$ $\mathrm{kg} /$ ha de $\mathrm{K}_{2} \mathrm{O}$ e $20 \mathrm{~kg} \mathrm{ha}^{-1}$ de nitrogênio $(\mathrm{N})$, como adubação de base e mais $130 \mathrm{~kg} \mathrm{ha}^{-1}$ de $\mathrm{N}$ aplicados em cobertura, divididos em três épocas, totalizando $150 \mathrm{~kg}$ $\mathrm{ha}^{-1}$ de N. A adubação considera as análises de solo com expectativa para produtividade de 7,0 $\mathrm{Mg} \mathrm{ha}^{-1}$ de matéria seca de pasto e de 4,0 $\mathrm{Mg} \mathrm{ha}^{-1}$ de grãos de soja. Bovinos jovens com peso médio de $200 \mathrm{~kg}$ peso vivo (PV) entraram na área no dia 02 de junho de 2014 para o pastejo contínuo, período em que a pastagem atingiu um acúmulo médio de $1500 \mathrm{~kg}$ de $\mathrm{MS} \mathrm{ha}^{-1}$, permanecendo por 152 dias.

A carga animal média dos últimos 14 anos de pastejo foi de 1297, 928, 601 e $342 \mathrm{~kg}$ de $\mathrm{PV} /$ ha para 
manter o pasto a 10, 20, 30 e $40 \mathrm{~cm}$ de altura, respectivamente, com poucas variações. Essas cargas de animais se traduzem em taxas de lotação de aproximadamente, 4,5; 3,0; 2,0 e 1,0 animais ha-1 considerando média $300 \mathrm{~kg}$ de PV. Durante o pastejo, a altura do pasto foi medida a cada 14 dias pelo método Sward stick (Bircham, 1981). Se a altura do pasto era menor ou maior que o valor estabelecido pelo tratamento, animais eram retirados ou adicionados, respectivamente.

Em 28 de novembro de 2014, foi realizada a semeadura da soja, cultivar Nideira 5909, com espaçamento de $0,45 \mathrm{~m}$ e população média de $300 \mathrm{mil}$ plantas por hectare. A adubação para a soja tinha sido realizada na semeadura da aveia cultivada anteriormente e o controle de plantas daninhas, pragas e doenças foi realizado de acordo com recomendações técnicas. A colheita ocorreu em 17 de abril de 2015, determinando a produtividade de grãos. Esses procedimentos são repetidos desde 2001, com pequenas alterações do cultivar de soja e da quantidade e época de adubação.

Foi determinado os atributos físicos do solo, densidade do solo, macroporosidade, textura e matéria orgânica do solo, mostrados na Tabela 1 (EMBRAPA, 2011; RUIZ, 2005). A densidade do solo foi determinada pela divisão da massa de solo seca a $105{ }^{\circ} \mathrm{C}$ por 48 horas pelo volume do anel (Equação 1). Amostras com estrutura preservada foram coletadas em trincheiras, usando anéis com volume de $100 \mathrm{~cm}^{-3}$, sendo saturadas com água por 48 horas, e submetidas a uma tensão de 6 $\mathrm{kPa}$ em mesa de tensão. A porosidade total foi considerada o volume de saturação, determinado pela relação entre o conteúdo volumétrico de água na amostra saturada, o volume do anel e a amostra seca em estufa por 48 horas a $105{ }^{\circ} \mathrm{C}$ (Equação 2). A microporosidade foi considerada a água retida após a tensão de $6 \mathrm{kPa}$ (poros com $\emptyset \leq 0,05 \mathrm{~mm}$; Equação 3) e a macroporosidade determinada por diferença entre porosidade total e microporosidade (Equação 4).

Foi determinada a biomassa da pastagem sobre solo, nos meses de pastejo, coletando uma área de 0,5 $\mathrm{m}^{2}$, com 3 repetições por parcela totalizando nove por tratamento. As amostras coletadas foram secas em estufa até peso constante e após calculado a biomassa vegetal seca, apresentada em $\mathrm{kg} \mathrm{ha}{ }^{-1}$.
As avaliações de temperatura do solo (Ts) e umidade volumétrica do solo $(\theta)$ foram realizadas durante dez meses, sendo seis meses no cultivo da aveia + azevém e quatro meses no cultivo soja. A Ts foi determinada com geotermômetros tipo espeto em dois momentos; na ausência de luz solar (04:00 às 6:00 horas) e na presença de luz solar (12:00 as 14:00 horas), nas camadas de 0-5, 5-10 e 10-20 cm, com três repetições por parcela, totalizando nove por tratamento e a coleta de dados em três dias seguidos por mês, sendo um dia em cada bloco. Isso ocorreu pela necessidade da coleta de dados dentro do período pré-estabelecido de duas horas em experimento com área de 22 ha.

A umidade do solo foi determinada em amostras coletadas em trincheiras abertas no solo, nas camadas de 0-5, 5-10 e 10-20 cm, em triplicata por parcela, secando o solo em estufa a $105^{\circ} \mathrm{C}$ por $48 \mathrm{~h} \mathrm{e}$ multiplicado pela densidade do solo para obter a $\theta$ volumétrica (Equação 5 e 6).

As equações utilizadas para determinar os atributos físicos foram:

$$
\rho=\frac{M s s}{v}
$$

em que $\rho$ é a densidade do solo em $\mathrm{Mg} \mathrm{m}^{-3}$; Mss é a massa de solo seco e $v$ é o volume do anel.

$$
P T=\text { Vsat. }
$$

(Equação 2)

em que PT é a porosidade total e V sat é o volume de saturação.

$$
M i c=\frac{M a}{v}
$$

em que Mic é a microporosidade, $M a$ é a massa da água contida em poros $<0,05 \mathrm{~mm}$ e $v$ é o volume da amostra.

$$
\text { Mac }=P t-M i c
$$

em que Mac é a macroporosidade.

$$
\boldsymbol{U} \boldsymbol{g}=\frac{M a}{M s s}
$$

em que $U g$ é a umidade gravimétrica do solo em $\mathrm{kg} \mathrm{kg}^{-1}$.

$$
\boldsymbol{\theta}=\boldsymbol{U} \boldsymbol{g} * \boldsymbol{\rho}
$$

em que $\theta$ é a umidade volumétrica do solo.

Com os dados de Ts foi calculada a amplitude de temperatura do solo dia-noite $\left(\Delta \mathrm{T}_{\text {dia-noite }}\right)$ pela Equação: $\Delta \boldsymbol{T}_{\text {dia-noite }}=\boldsymbol{T} \boldsymbol{s}_{\text {dia }}-\boldsymbol{T} \boldsymbol{s}_{\text {noite }} \quad($ Equação 7$)$ 
Os dados climatológicos foram monitorados diariamente por uma estação meteorológica (Vantage Pro 2, Davis, Hayward, USA), instalada na área experimental, disponibilizando dados de temperatura do ar, precipitação, umidade relativa do ar, evapotranspiração e radiação solar, todos determinados e calculados pela estação meteorológica.
Os dados foram submetidos à análise de variância e quando significativos comparados pelo teste de Tukey $(p \leq 0,05)$. Também foram realizadas análises de regressão, utilizando o sigma plot, para observar a relação entre a Ts e a biomassa sobre o solo no pastejo.

Tabela 1. Caracterização dos atributos físicos do Latossolo Vermelho Distroférrico em sistema integrado soja-bovinos de corte no Sul do Brasil

\begin{tabular}{|c|c|c|c|c|c|c|c|c|c|c|c|c|c|c|c|}
\hline \multirow{3}{*}{$\begin{array}{c}\text { Ma } \\
\text { nej } \\
\text { o }\end{array}$} & \multirow[t]{2}{*}{$\begin{array}{l}\text { Arg } \\
\text { ila }\end{array}$} & \multirow[t]{2}{*}{$\begin{array}{c}\text { Silt } \\
\text { e }\end{array}$} & \multirow[t]{2}{*}{$\begin{array}{c}\text { Arei } \\
\mathbf{a}\end{array}$} & \multicolumn{3}{|c|}{$\begin{array}{l}\text { *Densidade do } \\
\text { solo }\left(\mathrm{Mg} \mathrm{m}^{-3}\right)\end{array}$} & \multicolumn{3}{|c|}{$\begin{array}{l}\text { *Porosidade total } \\
\qquad\left(\mathrm{m}^{3} \mathrm{~m}^{-3}\right)\end{array}$} & \multicolumn{3}{|c|}{$\begin{array}{l}\text { *Macroporosidade } \\
\left(\mathrm{m}^{3} \mathrm{~m}^{-3}\right)\end{array}$} & \multicolumn{3}{|c|}{$\begin{array}{l}\text { Matéria Orgânica } \\
\qquad\left(\mathrm{g} \mathrm{k}^{-1}\right)\end{array}$} \\
\hline & & & & $0-5$ & $5-10$ & $10-20$ & $0-5$ & $5-10$ & $10-20$ & $0-5$ & $5-10$ & $10-20$ & $0-5$ & $5-10$ & $10-20$ \\
\hline & \multicolumn{3}{|c|}{--------( $\left(\mathrm{g} \mathrm{kg}^{-1}\right)$------- } & & & & & & & & & & & & \\
\hline P10 & 613 & 144 & 243 & 1,32 & 1,41 & 1,41 & 0,52 & 0,49 & 0,49 & 0,14 & 0,13 & 0,12 & 27,6 & 13,9 & 11,8 \\
\hline P20 & 626 & 161 & 213 & 1,30 & 1,41 & 1,40 & 0,52 & 0,48 & 0,49 & 0,11 & 0,10 & 0,10 & 27,7 & 16,4 & 11,9 \\
\hline P30 & 635 & 143 & 222 & 1,24 & 1,38 & 1,41 & 0,56 & 0,51 & 0,50 & 0,17 & 0,14 & 0,11 & 29,3 & 17,0 & 11,4 \\
\hline P40 & 572 & 156 & 272 & 1,16 & 1,38 & 1,41 & 0,58 & 0,50 & 0,49 & 0,20 & 0,13 & 0,11 & 30,8 & 16,4 & 12,2 \\
\hline SP & 587 & 175 & 238 & 1,11 & 1,36 & 1,39 & 0,60 & 0,51 & 0,50 & 0,22 & 0,13 & 1,12 & 31,5 & 18,1 & 13,7 \\
\hline
\end{tabular}

\section{RESULTADOS E DISCUSSÕES}

A temperatura média do ar foi de $19,7{ }^{\circ} \mathrm{C}$ durante o período de maio de 2014 a março de 2015 e a precipitação foi regular durante esse período, com total de $2.282 \mathrm{~mm}$, estando acima da média histórica da região

(Figura 1a).
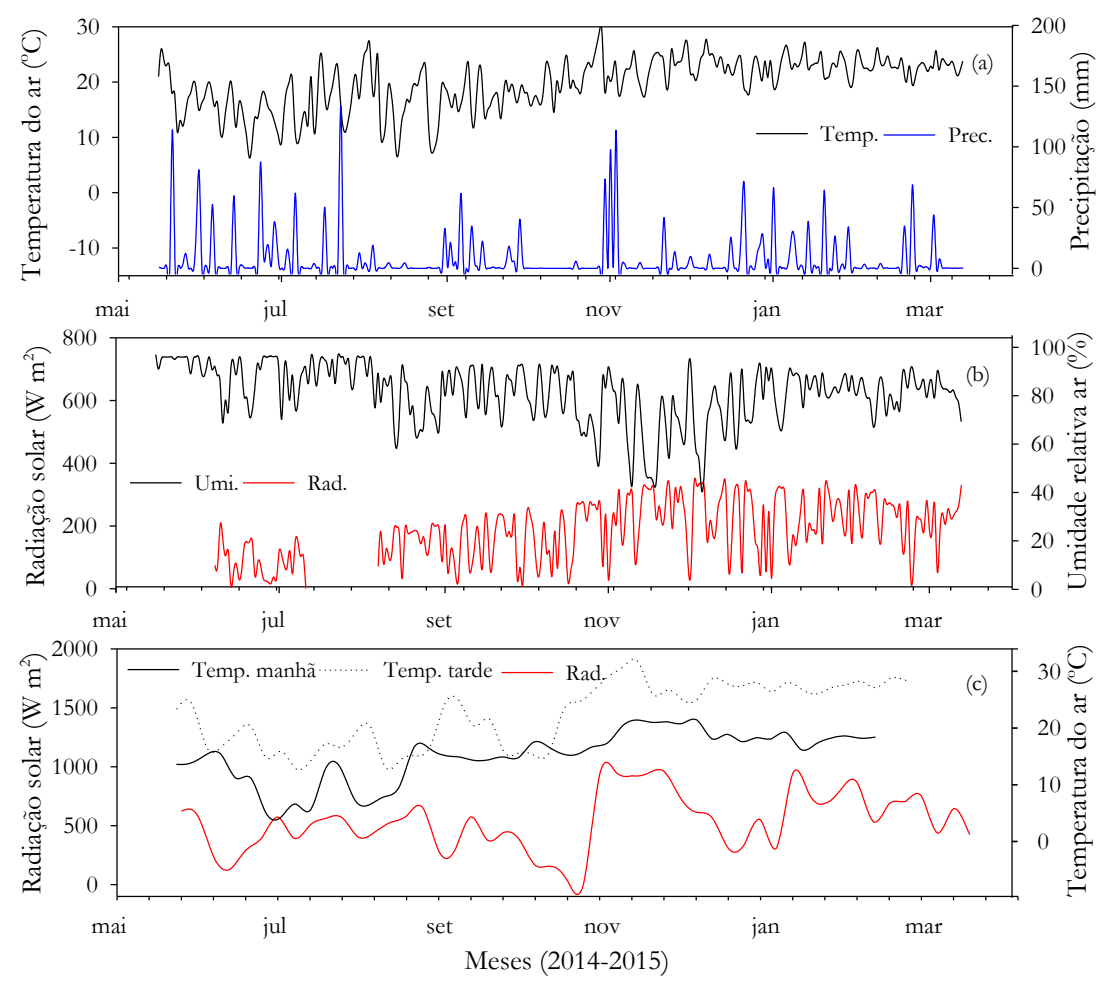

Figura 1. Temperatura do ar e precipitação média diária (a), radiação solar e umidade relativa do ar média diária (b), e radiação solar e temperatura do ar média dos 3 dias de determinação da umidade e temperatura do solo (c). 
A radiação solar aumentou, e a umidade do ar reduziu, a partir do mês de outubro (Figura 1b). Os dados no momento das amostragens mostram aumento da temperatura do ar no período da tarde acompanhado de aumento da radiação solar, principalmente a partir do mês de outubro (Figura 1c).

A cobertura do solo foi alterada de acordo com a altura de manejo do pasto (Tabela 2). Após o início do pastejo, no mês de junho, houve ajuste da biomassa da pastagem, seguindo as intensidades de pastejo, com menor biomassa no P10 e maior no SP. A menor biomassa sobre o solo reduz a sua proteção contra os processos erosivos e pode ter impacto direto no aumento da Ts durante o dia e resfriamento durante a noite. O resíduo final, considerando o mês de setembro, foi diferente entre os sistemas de manejo (Tabela 2).

Tabela 2. Biomassa seca durante o ciclo de pastejo em diferentes alturas de manejo do pasto no sistema integrado sojabovinos de corte em semeadura direta de longa duração (outono-inverno de 2014)

Manejo
do pasto $^{(1)}$

\begin{tabular}{ccccc}
\cline { 2 - 4 } & Junho & Julho & Agosto & Setembro \\
\hline P10 & 1,56 & 1,13 & 0,53 & 0,48 \\
P20 & 1,37 & 1,79 & 2,04 & 2,14 \\
P30 & 1,51 & 2,04 & 2,78 & 3,60 \\
P40 & 1,63 & 2,68 & 3,81 & 4,36 \\
SP & 1,83 & 2,84 & 4,55 & 5,81 \\
\hline
\end{tabular}

(1)P10, P20, P30, P40 corresponde à altura do pasto a 10, 20, 30, $40 \mathrm{~cm}$ respectivamente e SP, sem pastejo.

Estudos de Martins et al. (2015) mostraram que considerando o ganho de peso, qualidade de carcaça e disponibilidade de forragem o sistema com melhor desempenho foi o pasto mantido à $20 \mathrm{~cm}$ de altura. No entanto, para os atributos de solo, especialmente os físicos, o manejo do pasto à $30 \mathrm{~cm}$ de altura tem sido considerado adequado, e possivelmente isso tem relação com a adição de material orgânico e redução da compactação do solo.

A umidade do solo diferiu entre as alturas de manejo do pasto (Tabela 3).

Tabela 3. Umidade em camadas do solo(1) ao longo do tempo em diferentes alturas de manejo do pasto, no sistema integrado soja-bovinos de corte em semeadura direta de longa duração

\begin{tabular}{|c|c|c|c|c|c|c|c|c|c|c|}
\hline \multirow{4}{*}{ Manejo $^{(2)}$} & \multicolumn{10}{|c|}{ Umidade do solo $\left(\mathrm{m}^{3} \mathrm{~m}^{-3}\right)$} \\
\hline & \multicolumn{10}{|c|}{ Meses de avaliações (2014/15) } \\
\hline & Abr & Mai & Jun & Jul & Ago & Set & Dez & Jan & Fev & Mar \\
\hline & \multicolumn{10}{|c|}{------------------------------------------------------Camada $0-5$ cm------------------------------------------------------ } \\
\hline P10 & $0,34^{\text {ns }}$ & $0,34^{\mathrm{ns}}$ & $0,43^{\text {ns }}$ & $0,48^{\text {ns }}$ & $0,46^{\mathrm{ns}}$ & $0,40 \mathrm{a}$ & $0,25^{\mathrm{ns}}$ & $0,31^{\text {ns }}$ & $0,26 \mathrm{~b}$ & $0,28^{\text {ns }}$ \\
\hline P20 & 0,32 & 0,32 & 0,43 & 0,51 & 0,49 & $0,40 \mathrm{a}$ & 0,28 & 0,35 & $0,28 \mathrm{ab}$ & 0,30 \\
\hline P30 & 0,33 & 0,30 & 0,44 & 0,49 & 0,49 & $0,39 \mathrm{a}$ & 0,27 & 0,34 & $0,29 \mathrm{ab}$ & 0,30 \\
\hline P40 & 0,32 & 0,31 & 0,43 & 0,48 & 0,49 & $0,39 \mathrm{a}$ & 0,28 & 0,34 & $0,25 \mathrm{~b}$ & 0,28 \\
\hline \multirow[t]{2}{*}{ SP } & 0,31 & 0,31 & 0,45 & 0,48 & 0,44 & $0,31 \mathrm{~b}$ & 0,28 & 0,35 & $0,31 \mathrm{a}$ & 0,29 \\
\hline & \multicolumn{10}{|c|}{----------------------------------------------Camada 5-10 cm--------------------------------------------- } \\
\hline P10 & $0,36^{\mathrm{ns}}$ & $0,36^{\mathrm{ns}}$ & $0,41^{\text {ns }}$ & $0,40^{\mathrm{ns}}$ & $0,40^{\mathrm{ns}}$ & $0,37 \mathrm{ab}$ & $0,28 \mathrm{~b}$ & $0,35^{\text {ns }}$ & $0,30 \mathrm{~b}$ & $0,32^{\mathrm{ns}}$ \\
\hline $\mathbf{P} 20$ & 0,35 & 0,36 & 0,40 & 0,45 & 0,45 & $0,37 \mathrm{ab}$ & $0,31 \mathrm{ab}$ & 0,38 & $0,32 \mathrm{~b}$ & 0,33 \\
\hline P30 & 0,34 & 0,35 & 0,40 & 0,44 & 0,45 & $0,39 \mathrm{a}$ & $0,30 \mathrm{ab}$ & 0,36 & $0,32 \mathrm{~b}$ & 0,33 \\
\hline P40 & 0,34 & 0,35 & 0,39 & 0,43 & 0,44 & $0,40 \mathrm{a}$ & $0,31 \mathrm{ab}$ & 0,38 & $0,32 \mathrm{~b}$ & 0,34 \\
\hline \multirow[t]{2}{*}{ SP } & 0,36 & 0,37 & 0,44 & 0,44 & 0,43 & $0,33 \mathrm{~b}$ & $0,33 \mathrm{a}$ & 0,40 & $0,37 \mathrm{a}$ & 0,35 \\
\hline & \multicolumn{10}{|c|}{ 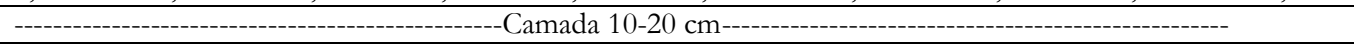 } \\
\hline P10 & $0,36^{\mathrm{ns}}$ & $0,36^{\mathrm{ns}}$ & 0,39 ns & 0,39 ns & $0,37 \mathrm{~ns}$ & $0,38^{\text {ns }}$ & $0,29 \mathrm{~b}$ & $0,37 \mathrm{~ns}$ & $0,32 \mathrm{~b}$ & $0,34^{\mathrm{ns}}$ \\
\hline $\mathbf{P} 20$ & 0,36 & 0,36 & 0,39 & 0,41 & 0,40 & 0,38 & $0,31 \mathrm{ab}$ & 0,38 & $0,33 \mathrm{~b}$ & 0,34 \\
\hline P30 & 0,37 & 0,37 & 0,39 & 0,41 & 0,40 & 0,39 & $0,31 \mathrm{ab}$ & 0,38 & $0,34 \mathrm{ab}$ & 0,34 \\
\hline P40 & 0,36 & 0,38 & 0,40 & 0,41 & 0,39 & 0,38 & $0,29 \mathrm{~b}$ & 0,36 & $0,33 \mathrm{~b}$ & 0,35 \\
\hline SP & 0,37 & 0,39 & 0,41 & 0,44 & 0,41 & 0,35 & $0,34 \mathrm{a}$ & 0,40 & $0,38 \mathrm{a}$ & 0,36 \\
\hline
\end{tabular}

(1) Larossolo Vermelho Distroférrico. (2) P10, P20, P30, P40 corresponde à altura do pasto a 10, 20,30, $40 \mathrm{~cm}$ respectivamente e SP, sem pastejo.

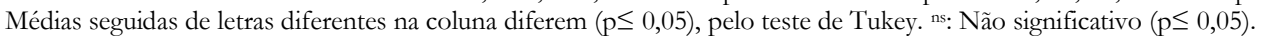


Nos meses de setembro, (camadas 0-5 e 5-10 $\mathrm{cm}$ ), com maior umidade nas áreas pastejada em relação ao SP, dezembro (camadas 5-10 e 10-20 cm), com menor umidade no $\mathrm{P} 10$ em relação ao $\mathrm{SP}$ e em fevereiro (camadas 0-5, 5-10 e 10-20 cm), com maior umidade no SP em relação as áreas pastejadas (Tabela 3).

A maior umidade do solo em sistemas de manejo com maior cobertura do solo é esperada e isso está relacionada à sua maior proteção da radiação solar, que interfere na evapotranspiração do solo (ANDRADE et al., 2011), como ocorreu nos meses de dezembro e fevereiro. Entretanto, a maior quantidade de biomassa sobre o solo $\left(5,81 \mathrm{Mg} \mathrm{ha}^{-1}\right.$ no SP) reduziu a umidade do solo em setembro. Isso ocorreu porque as precipitações menores de $20 \mathrm{~mm}$, ocorrida nos dias de avaliações, não atingiram o solo em sua totalidade.
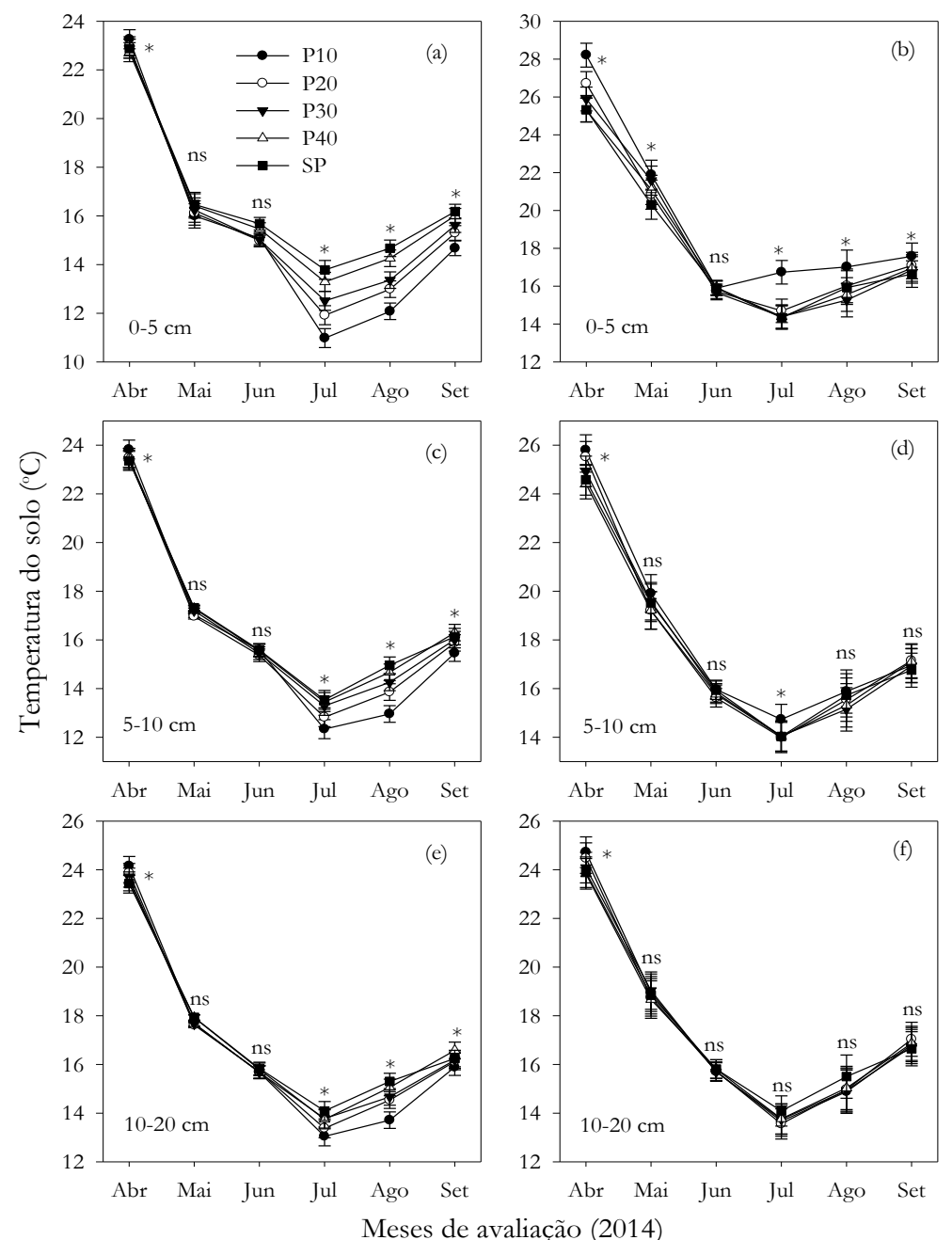

Figura 2. Temperatura do solo(1), camada 0-5 cm das 4 às 6 horas (a) e das 12:00 as 14:00 (b), camada 5-10 cm, das 4 às 6 horas (c) e das 12:00 as 14:00 (d) e camada 10-20 cm, das 4 às 6 horas (e) e das 12:00 as 14:00 (f), durante o desenvolvimento da cultura da aveia, em diferentes alturas de manejo do pasto no sistema integrado soja-bovinos de corte em semeadura direta de longa duração.

(1) Latossolo Vermelho Distroférrico. P10, P20, P30, P40 corresponde à altura do pasto a 10, 20, 30, 40 cm respectivamente e SP, sem pastejo. *: significativo para tratamentos da altura do pasto; ns: não significativo. Barras são o DMS ( $\mathrm{p} \leq 0,05)$, Tukey. 
As alterações na Ts entre os manejos da altura do pasto foram maiores após o mês de julho no período diurno e noturno, aproximadamente 30 dias após o início do pastejo (Figura 2). Ocorreu menor Ts no período noturno nos pastejos P10 e P20 nos meses de abril, julho, agosto e setembro (camadas 0-5, 5-10 e 10$20 \mathrm{~cm}$ ). No período diurno os valores se inverteram, com maior Ts no P10 em abril (camadas 0-5, 5-10 e 10$20 \mathrm{~cm}$ ), maio (camada $0-5 \mathrm{~cm}$ ), julho (camadas $0-5$ e 5 $10 \mathrm{~cm}$ ) e agosto e setembro (camada $0-5 \mathrm{~cm}$ ). As alterações em abril, próximo à semeadura da aveia, estão, possivelmente, relacionadas com a baixa cobertura do solo por resíduos de soja, observado em outros anos por Martins et al. (2015) e as altas temperaturas nesse período (Figura 2). A não alteração na Ts nos períodos noturno e diurno e em nenhuma das camadas no mês de junho coincide com a época de entrada dos animais, onde as plantas em crescimento protegem o solo, e também com um dos meses mais frios.

Durante o cultivo de soja, houve diferenças de Ts em ambos os períodos estudados e camadas avaliadas (Figura 3).
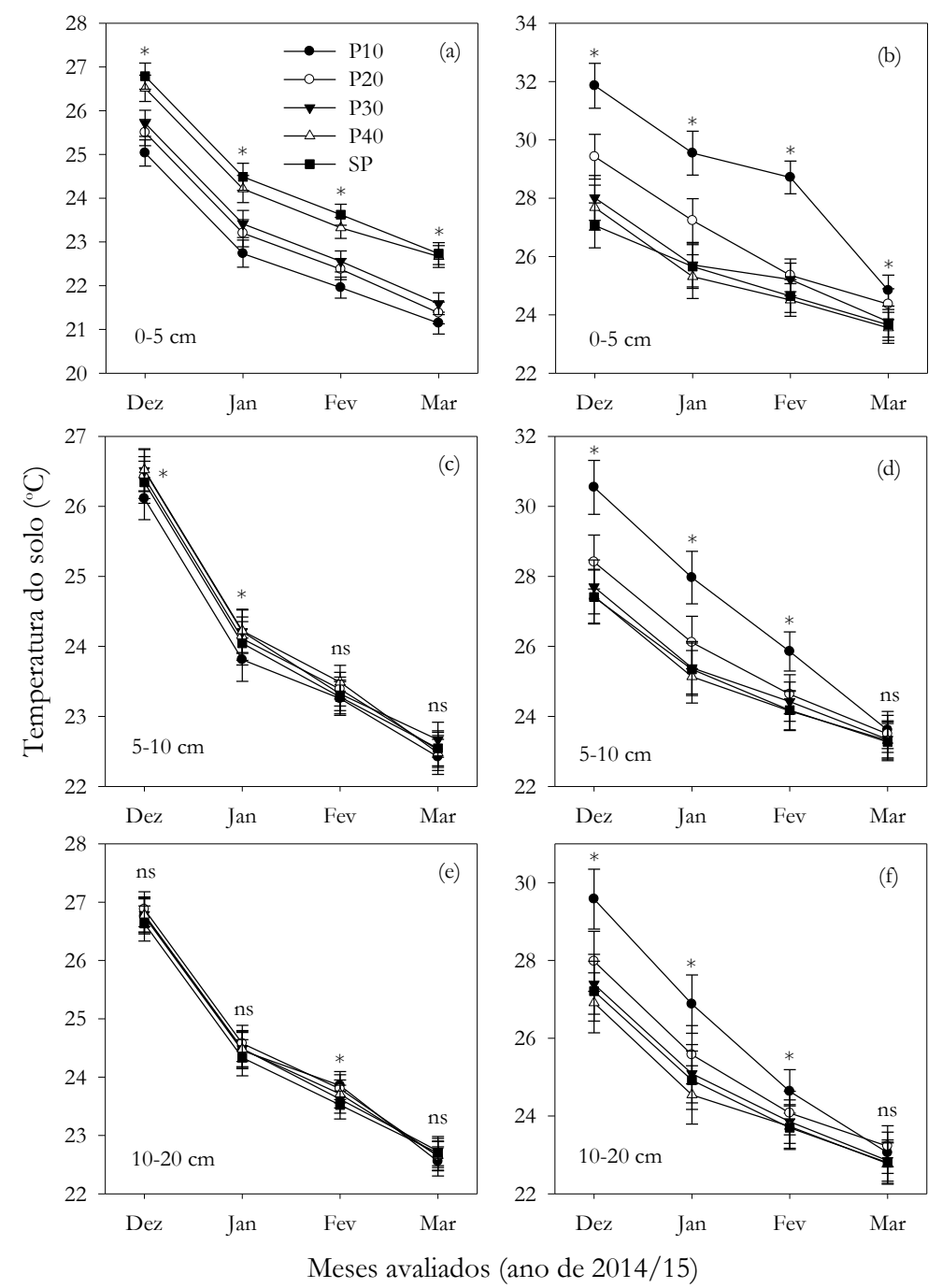

Figura 3. Temperatura do solo( $(1)$, camada $0-5 \mathrm{~cm}$ das 4 às 6 horas (a) e das 12:00 as 14:00 (b), camada 5-10 cm, das 4 às 6 horas (c) e das 12:00 as 14:00 (d) e camada 10-20 cm, das 4 às 6 horas (e) e das 12:00 as 14:00 (f), durante o desenvolvimento da cultura da soja, em diferentes alturas de manejo do pasto no sistema integrado soja-bovinos de corte em semeadura direta de longa duração.

(1) Latossolo Vermelho Distroférrico. P10, P20, P30, P40 corresponde à altura do pasto a 10, 20, 30, 40 cm respectivamente e SP, sem pastejo. *: significativo na comparação de tratamentos da altura do pasto; ns: não significativo. Barras: DMS ( $\mathrm{p} \leq 0,05)$, Tukey. 
No período noturno, ocorre menor Ts nos pastejos mais intensos em dezembro e janeiro (0-5 e 5$10 \mathrm{~cm})$, fevereiro $(0-5$ e $10-20 \mathrm{~cm})$ e fevereiro e março (0-5 e 5-10 cm). No período diurno houve maior Ts, especialmente no P10 e P20, em dezembro, janeiro e fevereiro (0-5, 5-10 e 10-20 cm) e março $(0-5 \mathrm{~cm})$.

A menor Ts no início do desenvolvimento da soja, principalmente no P10 e P20, estão relacionados, possivelmente, ao baixo volume de biomassa residual sobre o solo, dados observados por Martins et al. (2015), podendo aumentar a condutividade térmica dos solo (ABUEL-NAGA et al., 2009). A Ts pode afetar a germinação das sementes e o desenvolvimento das plantas, onde a temperatura ideal para germinação de sementes de soja varia de 20-30 ${ }^{\circ} \mathrm{C}$ (SETIYONO et al.,
2010), que aliado a umidade adequada contribui para a maior e mais rápida germinação de sementes (TYAGI; TRIPATHI, 1983).

Foi observada Ts maior de $28^{\circ} \mathrm{C}$ durante o dia no mês de dezembro em todas as camadas no P10 e P20, sendo que no P10 atingiu $32{ }^{\circ} \mathrm{C}$, na camada de $0-5 \mathrm{~cm}$. Essa alteração na Ts pode ajudar a explicar a redução de plantas $/ \mathrm{m}^{2}$ mesma área experimental, observados por Martins et al. (2015), com 38 plantas $/ \mathrm{m}^{2}$ no P10 e 45 plantas $/ \mathrm{m}^{2}$ no SP. Ribas et al. (2015) observaram, em Santa Maria - RS, região próxima a este estudo, Ts (camada de 0-5 cm, às 15:00 horas) de $40{ }^{\circ} \mathrm{C}$ em solo sem cobertura e irrigação, e $28{ }^{\circ} \mathrm{C}$ em solo com cobertura de palha, em outubro.

Houve diferença de variação de Ts dia-noite $\left(\Delta \mathrm{T}_{\text {dia-noite }}\right)$, onde os pastejo intensos (P10 e P20) apresentaram os maiores valores (Figura 4).

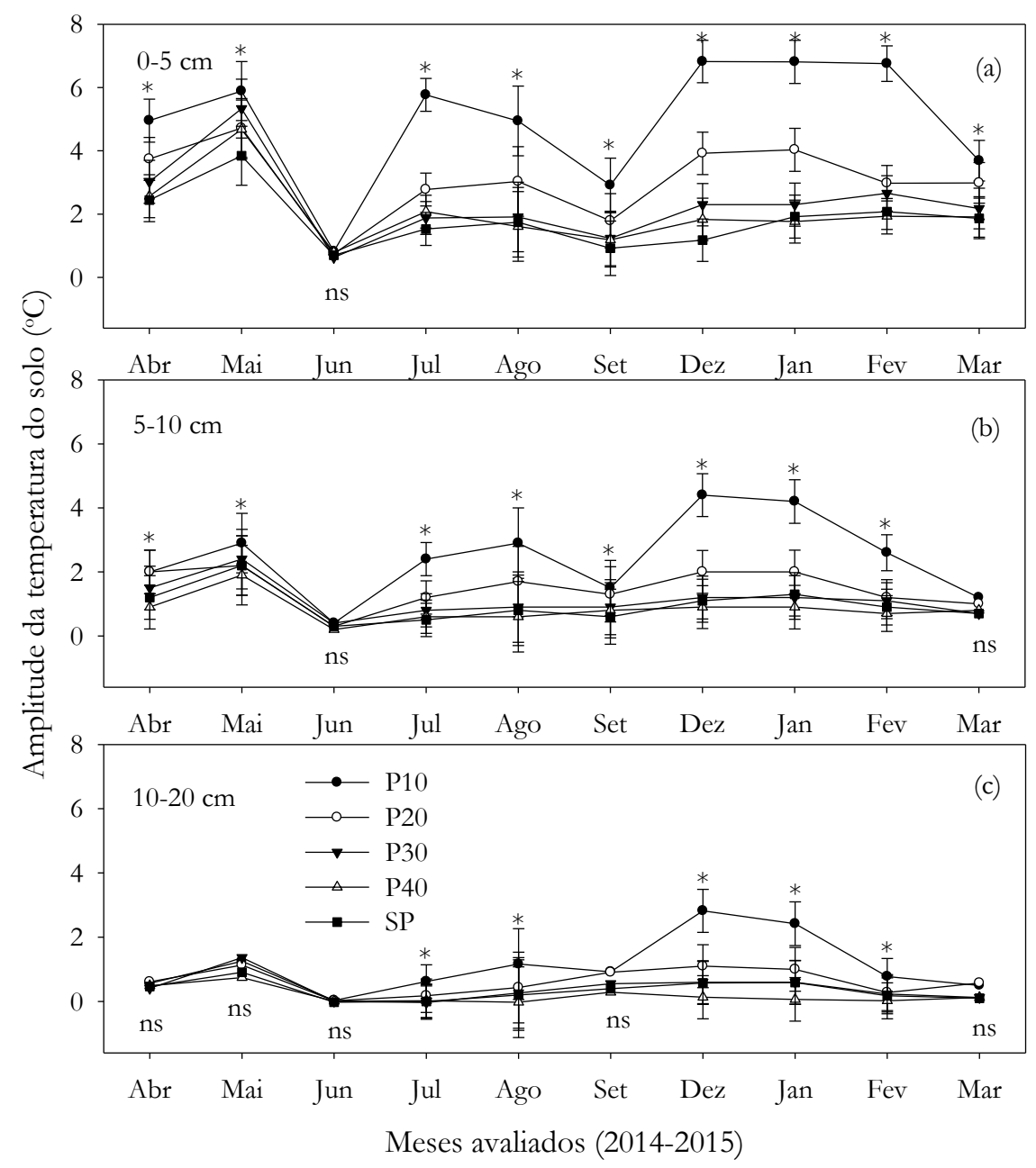

Figura 4. Amplitude da temperatura do solo(1) nas camadas 0-5 cm (a), 5-10 cm (b) e 10-20 cm (c) durante o desenvolvimento da aveia preta e da soja, em diferentes alturas de manejo do pasto no sistema integrado soja-bovinos de corte em semeadura direta de longa duração.

(1) Latossolo Vermelho Distroférrico. P10, P20, P30, P40 corresponde à altura do pasto a 10, 20, 30, $40 \mathrm{~cm}$ respectivamente e SP, sem pastejo. *; significativo na comparação de tratamentos de manejo da altura do pasto; ns: não significativo. Barras são DMS ( $\mathrm{p} \leq 0,05)$, Tukey. 
Essas diferenças ocorreram nos meses de abril e maio (camadas 0-5 e 5-10 cm), julho e agosto (camada 0-5, 5-10 e 10-20 cm), setembro (camadas 0-5, 5-10 cm), dezembro, janeiro e fevereiro (camadas $0-5,5-10$ e 10$20 \mathrm{~cm}$ ) e março (camada 0-5 cm). Valor expressivo ocorreu (camada 0-5 cm) (Figura 4a) no período pastejado e nos meses mais quentes no cultivo soja.

As maiores amplitudes ocorreram no pastejo intenso e no pastejo moderado P20, devido a redução da cobertura do solo. O maior contato das partículas aumenta a condutividade térmica (ABUEL-NAGA et al., 2009), que na parte mineral do solo é em média 1,7 $\mathrm{W} / \mathrm{m}{ }^{\circ} \mathrm{K}$. As variações na Ts, em curto tempo, estão relacionadas a atividade dos microrganismos no solo, medidos pelo fluxo de $\mathrm{CO}_{2}$ (CURIEL YUSTE et al., 2007). Em curto período, a decomposição da MOS foi controlada pela temperatura nos períodos de chuva e pelo efeito da água e da temperatura no período de seca (CURIEL YUSTE et al., 2007).

As alterações na biomassa se relacionaram com a amplitude da Ts, (Figura 5).

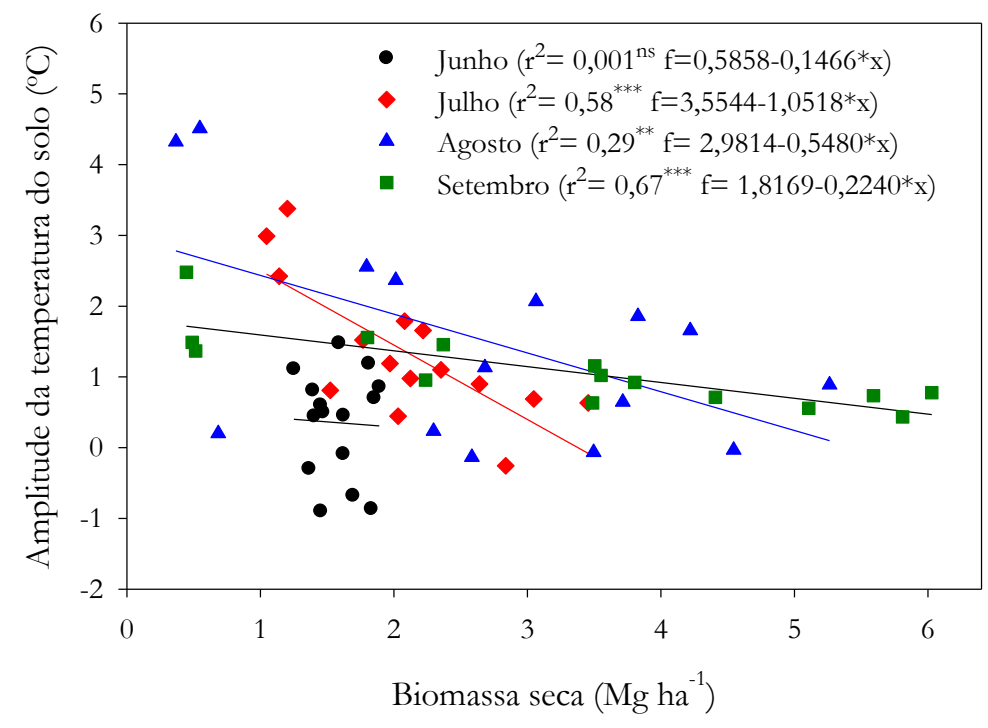

Figura 5. Relação da biomassa seca sobre o solo( ${ }^{(1)}$ e a amplitude de temperatura dia-noite ( $\Delta$ Tdia-noite) da camada 0-20 $\mathrm{cm}$, em diferentes alturas de manejo do pasto no sistema integrado soja-bovinos de corte em semeadura direta de longa duração.

(1) Latossolo Vermelho Distroférrico. ns: não significativo. ${ }^{* *}$ : significativo pelo teste de tukey $(\mathrm{p} \leq 0,05)$. ${ }^{* * *}$ : significativo pelo teste de tukey ( $\mathrm{p} \leq$ $0,01)$.

Nos meses de julho, agosto e setembro houve relação negativa $(\mathrm{p} \leq 0,05)$ da biomassa seca com $\Delta \mathrm{T}_{\text {dia- }}$ noite. Apenas no mês de junho não houve relação da a biomassa seca com a $\Delta \mathrm{T}_{\text {dia-noite }}(\mathrm{p} \leq 0,05)$, indicando que o aumento da proteção do solo dos raios solares ajudou a reduzir o efeito da radiação solar no solo. Assim, o manejo do pasto está diretamente relacionado com a Ts e principalmente, com a variação de temperatura no solo e, possivelmente, com o fluxo de calor no solo.

\section{CONCLUSÕES}

Os sistemas de manejo do pasto alteram a quantidade de biomassa sobre o solo durante e ao final do ciclo de pastejo, em que o pastejo intenso é o que mais reduziu a cobertura do solo.

A redução da cobertura do solo pelo pastejo não tem grande impacto na umidade do solo, no entanto alterou a temperatura no perfil do solo nos períodos noturno e diurno, especialmente no pastejo intenso e no pastejo moderado $(20 \mathrm{~cm})$, que resultam em temperatura do solo mais alta. Esse efeito persistiu durante o cultivo da soja, com maior ocorrência no período diurno. 
A amplitude da temperatura do solo aumenta com o manejo da altura do pasto, tanto no ciclo de pastejo como nos meses iniciais de desenvolvimento da soja, sendo maiores no pastejo intenso e no pastejo moderado.

\section{AGRADECIMENTOS}

Os autores agradecem a Fazenda Espinilho, localizada em são Miguel das Missões-RS, ao grupo de pesquisa em sistemas integrados de produção agropecuária (SIPA) pela ajuda na condução do experimento. Às agências financiadoras Capes, CNPq e Fundação Agrisus.

\section{REFERÊNCIAS BIBLIOGRÁFICAS}

ABUEL-NAGA, H. M.; BERGADO, D. T.; BOUAZZA, A.; PENDER, M. J. Thermal conductivity of soft Bangkok clay from laboratory and field measurements. Engineering Geology, v. 105, p. 211-219, 2009.

ANDRADE, J. G. DE; SEGUÍ, J. P.; CARLESSO, R.; TROIS, C.; KNIES, E. Perdidas de agua por evaporación en maíz con siembra convencional y directa para diferentes niveles de cobertura muerta. I. Resultados experimentales. Revista Ciencias Técnicas Agropecuarias, v. 20, n. 2, p. 60-64, 2011.

BAO, X.; ZHU, X.; CHANG, X.; et al. Effects of soil temperature and moisture on soil respiration on the Tibetan plateau. PLoS ONE, v. 11, n. 10, p. 9-15, 2016.

BONETTI, J. DE A.; PAULINO, H. B.; DE SOUZA, E. D.; CARNEIRO, M. A. C.; DA SILVA, G. N. Influência do sistema integrado de produção agropecuária no solo e na produtividade de soja e braquária. Pesquisa Agropecuária Tropical, v. 45, n. 1, p. 104-112, 2015.

CARNEIRO, R. G.; MOURA, M. A. L.; SILVA, V. D. P. R.; et al. Variabilidade da temperatura do solo em função da liteira em fragmento remanescente de mata atlântica. Revista Brasileira de Engenharia Agrícola $e$ Ambiental, v. 18, n. 1, p. 99-108, 2014.
CEMETRS - Conselho estadual de meteorologia do Rio Grande do Sul. Atlas Climático do Rio Grande do Sul. Disponível

em: http://www.cemet.rs.gov.br/upload/20130816144 4455 precipitacao.pdf. Acesso em: 24 jan. 2017.

CURIEL YUSTE, J.; BALDOCCHI, D. D.; GERSHENSON, A.; et al. Microbial soil respiration and its dependency on carbon inputs, soil temperature and moisture. Global Change Biology, v. 13, n. 9, p. 2018-2035, 2007.

EMBRAPA - Empresa Brasileira de Pesquisa Agropecuária. Centro Nacional de Pesquisa de Solos. Manual de métodos de análise de solos. 2. ed. revisada. Rio de Janeiro: Embrapa CNPS, Documentos, 132, 2011. 230 p.

EMBRAPA - Empresa Brasileira de Pesquisa Agropecuária. Sistema brasileiro de classificação de solos. 3.ed. Brasília, 2013. 353 p.

LICHT, M. A.; AL-KAISI, M. Strip-tillage effect on seedbed soil temperature and other soil physical properties. Soil and Tillage Research, v. 80, n. 2, p. 233-249, 2005.

MARTINS, A. P., KUNRATH, T. R., ANGHINONI, I., CARVALHO, P. C. F. (Eds.). Integração soja-bovinos de corte no sul do Brasil. Porto Alegre: Gráfica RJR, 2015. 104 p.

PEZZOPANE, J.E.M.; REIS, G.G.; REIS, M.G.F.; COSTA, J.M.N.; CHAVES, J.H. Temperatura do solo no interior de um fragmento de floresta secundária semidecidual. Revista Brasileira de Agrometeorologia, Santa Maria, v.10, n.1, p.1-8, 2002.

RIBAS, G. G.; STRECK, N. A.; SILVA, S. D. DA; ROCHA, T. S. M. DA; LANGNER, J. A. Temperatura do solo afetada pela irrigação e por diferentes coberturas. Engenharia Agrícola, v. 35, n. 5, p. 817-828, 2015.

RUIZ, H. A. Incremento da exatidão da análise granulométrica do solo por meio da coleta da suspenso (silte + argila). Revista Brasileira de Ciência do Solo, v. 29, n. 2, p. 297-300, 2005.

SETIYONO, T. D.; CASSMAN, K. G.; SPECHT, J. E.; et al. Simulation of soybean growth and yield in nearoptimal growth conditions. Field Crops Research, v. 119, n. 1, p. 161-174, 2010. 
TYAGI, S. K.; TRIPATHI, R. P. Effect of temperature on soybean germination. Plant and Soil, v. 74, n. 2, p. 273-280, 1983.

VEIGA, M.; REINERT, D. J.; REICHERT, J. M. Tillage Systems and Nutrient Sources Affecting Soil Cover, Temperature and Moisture in a Clayey Oxisol Under Corn. Revista Brasileira De Ciência do Solo, v. 34, n. 6, p. 2011-2020, 2010. 